\title{
PENGARUH LATIHAN ZUMBA TERHADAP Nilai FEV1 (Forced Expiratory Volume in one second)
}

\author{
${ }^{1}$ Yusnia Jayanti \\ ${ }^{2}$ Jimmy F. Rumampuk \\ ${ }^{2}$ Wenny Supit \\ ${ }^{1}$ Kandidat Skripsi Fakultas Kedokteran Universitas Sam Ratulangi Manado \\ ${ }^{2}$ Bagian Fisika Fakultas Kedokteran Universitas Sam Ratulangi Manado \\ Email: yusniajayanti.yj@gmail.com
}

\begin{abstract}
The modern technology brings negative impact to human life that is the lack of physical activity which is not good for health and can cause varieties of diseases. Some studies show that lack of physical activity can lower pulmonary resistance and also a major cause of morbidity and mortality. Zumba is a Latine-inspired danse workout first developed in Columbia. The improvement of respiratory muscle endurance is gained from physical exercise . One asessment is a measurement of lung function FEV1 ( Forced expiratory volume in one Second ) which can provide information on the maximum rate of air flow in the lung. This study have a purpose to find out the influence of zumba exercise against FEV1 value of female students year 2013 Medical Faculty of Nursing Science Sam Ratulangi University hwo with less of physical or sport activities and meet the inclusion criteria. This was an experimental study with one group pre and post test design. Data was analyzed by paired t test using SPSS. The results showed significant differences between the average values of FEV 1 before and after 2 weeks of zumba exercise with $P=0,044(P<0.05)$. Conclusion: There was an increase of FEV 1 value after 2 weeks of Zumba exercise.
\end{abstract}

Keywords: physical exercise, FEV1, Zumba.

Abstrak: Kemajuan teknologi moderen membawa dampak negatif bagi masyarakat yaitu Kurangnya aktifitas fisik yang dapat berdampak buruk bagi kesehatan yaitu timbulnya berbagai penyakit. Beberapa penelitian menunjukkan berkurangnya aktifitas fisik dapat menurunkan daya tahan paru serta merupakan penyebab utama morbiditas dan mortalitas. Zumba merupakan latihan tari Latin yang terinspirasi pertama kali dan dikembangkan di Columbia. Peningkatan daya tahan otot pernapasan dapat diperoleh dari latihan fisik. Salah satu penilaian fungsi paru adalah pengukuran FEV1 (Forced Expiratory Volume in one Second) yang dapat memberikan informasi tentang laju aliran udara maksimal dalam paru. Penelitini ini ber tujuan untuk mengetahui pengaruh latihan zumba terhadap nilai FEV1 pada Mahasiswi Program Studi Ilmu Keperawatan angkatan 2013 Universitas Sam Ratulangi yang kurang melakukan aktivitas fisik atau olahraga dan memenuhi kriteria. Metode penelitian ini bersifat eksperimental dengan rancangan one group pre and post test design. Data dianalisis dengan uji t berpasangan menggunakan SPSS. Hasil penelitian ini menunjukkan perbedaan signifikansi antara nilai rata-rata FEV1 sebelum dan setelah 2 minggu latihan zumba $P=$ $0,04(P<0,05)$. Simpulan: Terdapat peningkatan nilai FEV1 sesudah 2 minggu latihan zumba.

Kata kunci : aktifitas fisik, FEV1, Zumba.

Kemajuan teknologi moderen saat ini telah membawa konsekuensi tersendiri baik positif maupun negatif terhadap kesehatan manusia. Dari segi positif, dengan adanya kemajuan teknologi maka banyak kegiatan yang menjadi lebih mudah dan lebih cepat untuk dilakukan. Dampak negatifnya ialah masyarakat menjadi malas untuk bergerak. $^{1}$ 
Kegiatan yang kurang melakukan aktitivitas akan berdampak pula bagi kesehatan seperti timbul penyakit kardiovaskular, kanker, penyakit pernafasan kronis, penyakit pencernaan dan diabetes. ${ }^{2}$ Saat ini penyakit tidak menular (PTM) menjadi penyebab utama kematian secara global. ${ }^{2,3}$ Menurut World Health Organisation (WHO), kematian akibat Penyakit Tidak Menular (PTM) diperkirakan akan terus meningkat. Pada tahun 2030 diprediksi akan ada 52 juta jiwa kematian per tahun karena penyakit tidak menular. Peningkatan kejadian PTM berhubungan dengan peningkatan faktor risiko akibat perubahan gaya hidup seiring dengan perkembangan dunia yang makin modern. ${ }^{2,4}$

Aktivitas fisik yang teratur dapat menyebabkan perbaikan kebugaran jasmani. ${ }^{5}$ Beberapa contoh dari aktivitas fisik aerobik adalah bersepeda, berjalan, jogging, lari dan Zumba. Berolahraga merupakan cara yang sangat baik untuk meningkatkan vitalitas fungsi paru. Olahraga merangsang pernapasan yang dalam dan menyebabkan peningkatan volume paru-paru. Peningkatan fungsi paru bisa disebabkan peningkatan kekuatan otot pernapasan. ${ }^{6}$

Dewasa ini banyak sekali programprogram latihan fisik yang ditawarkan, diantaranya senam Zumba yang saat ini banyak diminati oleh kalangan wanita, dalam survey yang dilakukan pada tahun 2013 mengenai tren kebugaran di seluruh dunia, zumba menempati peringkat kedua belas. ${ }^{7}$ Zumba adalah latihan tari Latin yang pertama kali dikembangkan di Columbia oleh seorang pelatih kebugaran Alberto "Beto" Perez. Zumba saat ini telah dilakukan oleh lebih dari 12 juta orang, di 110.000 lokasi, di 125 negara di Seluruh dunia. $^{8}$

Gerakan zumba merupakan gabungan antara tarian salsa, ramba dan merengue dengan menggunakan otot-otot

\section{METODE PENELITIAN}

Jenis penelitian yang digunakan tubuh seperti otot pinggul, pinggang, dan kaki. Zumba juga dikombinasikan dengan gerakan pengencangan otot-otot tubuh seperti otot perut, punggung, paha, betis, otot tebal di bagian dada (pectoralis) dan sebagainya. Zumba termasuk tarian yang dapat dengan cepat membakar kalori dan lemak pada tubuh karena gerakan dalam tarian zumba ini bersifat kardio seperti meloncat, berputar, bergerak cepat dan sebagainya. para peneliti menemukan bahwa Zumba kebugaran membakar ratarata 369 kalori atau sekitar 9,5 kkal per menit . Rata-rata HR adalah 154 denyut per menit (bpm). Rata-rata VO2max (ml . $\mathrm{kg}^{-1}$. $\min ^{-1}$ ) 47,2. Latihan Zumba ini dilakukan 32-52 menit dalam sekali latihan. Saat berlatih tarian Zumba akan mengeluarkan keringat dan pembakaran kalori lebih banyak. Dengan latihan Zumba tiga kali seminggu dalam satu bulan dapat menurunkan $3 \mathrm{~kg}$ berat badan. ${ }^{8-10}$

Perubahan-perubahan volume dan kapasitas paru yang terjadi selama bernapas dapat menggunakan alat spirometer. ${ }^{11}$ Nilai kapasitas seluruh paru pada wanita kira-kira 20-25\% lebih kecil daripada pria, dan lebih besar lagi pada orang yang atletis dan bertubuh besar daripada orang yang bertubuh kecil. ${ }^{12}$ Pada penelitian sebelumnya juga didapatkan Hasil pengujian hubungan nilai kapasitas vital paru, berat badan dan tinggi badan menunjukkan hubungan yang bermakna dan cukup kuat. ${ }^{13}$ Salah satu penilaian fungsi paru adalah pengukuran FEV1 (Forced Expiratory Volume in One Second) yang dapat memberikan informasi tentang laju aliran udara maksimal dalam paru. $^{14}$

Berdasarkan latar belakang di atas
penulis tertarik untuk melakukan
penelitian tentang pengaruh senam zumba
terhadap FEV1 (Forced Expiratory Volume in
one second).

dalam penelitian yaitu penelitian eksperimental dengan rancangan one 
group test pre and post test design. Penelitian ini dilakukan di bulan November 2013. Sampel penelitian yaitu mahasiswa Program Studi Ilmu Keperawatan Universitas Sam Ratulangi angkatan 2013 yang memenuhi kriteria. Kriteria inklusi : Wanita,Usia 16 - 21 tahun, IMT 18,5 - 22,9 (Normal), Tidak memiliki riwayat penyakit paru, Belum perna mengikuti latihan zumba sebelumnya, Tidak aktif dalam aktivitas fisik (olahraga). Kriteria eksklusi : IMT $18,5<$ dan $>22,9\left(\mathrm{~kg} / \mathrm{m}^{2}\right)$, Pada saat penelitian (pemeriksaan fungsi paru) sedang menderita penyakit pernapasan (Bronchitis, radang paru, TBC paru, Asma, Alergi), Aktif dalam aktivitas fisik atau olahraga. Jumlah sampel adalah 20 orang. ${ }^{15}$ Lokasi Penelitian dilaksanakan di Aulah Fakultas Kedokteran UNSRAT Manado.

Prosedur penelitian yaitu, (1)Pencarian alat Spirometri, (2)Pencarian sampel sebagai subjek penelitian dalam penelitian, (3)Sosialisasi tujuan penelitian kepada subjek penelitia, (4)Penyaringan Responden menggunakan Quesioner, (5)Pencarian instruktur zumba pada pusatpusat kebugaran dan studio zumba di kota Manado, (6)Penjelasan prosedur dan tujuan penelitian kepada intruktur zumba, (7)Pengisian dan penandatanganan informed consent sebagai tanda persetujuan ikut serta dalam penelitian, (8)Pengukuran berat badan dan tinggi badan dilakukan dibagian Ilmu Gizi Fakultas Kedokteran Universitas Sam Ratulangi Manado, (9)Pengisian kuesioner untuk penyaringan subjek penelitian.

Tahap perlakuan : (1)Latihan dilaksanakan setiap hari senin, rabu dan jumat pada pukul 14.00 WITA, (2)Latihan

\section{HASIL DAN BAHASAN}

A. Gambaran Sampel

Subjek yang diteliti yaitu mahasiswa berusia 16-21 tahun dimana pada usia seperti ini perkembangan dan pertumbuhan seseorang masih berlangsung. Rata-rata berat badan dipimpin oleh seorang instruktur Zumba yang telah memiliki sertifikat resmi dan latihan dilakukan selama 60 menit.

Pemeriksaan Fungsi paru menggunakan spirometri dilaksanakan pada tanggal 17 November 2013 sehari sebelum responden diberi perlakuan dan tanggal 29 November 2013 sehari setelah 2 minggu latihan Zumba. Pemeriksaan nilai FEV1 menggunakan spirometer elektronik. Sebelum melakukan pemeriksaan spirometri ada beberapa hal yang harus disiapkan: (1)siapkan alat spirometer lengkap dengan kertas grafik dan mouthpiece, (2)Hidupkan alat, biarkan \pm 10 menit, (3)Masukkan Data responden : ID, umur, tinggi badan, berat badan, jenis kelamin, (4)Pasien harus dalam keadaan sehat, tidak sedang dalam kondisi sakit pernapasan seperti flu atau infeksi saluran napas bagian atas lainnya, (5)hati-hati terhadap penderita asma karena dapat memicu serangan asma, (6)Responden dalam posisi berdiri dan menggunakan pakaian longgar, (7)Pasang penjepit hidung, (8)Pasang mouth piece ke mulut dengan posisi bibir rapat pada mouthpiece agar tidak ada udara yang terbuang ke luar mulut, (9)Lakukan pernapasan biasa melalui alat (pernapasan melalui mulut), (10)Responden menarik napas sedalamdalamnya dan kemudian menghembuskan napas secara cepat dan dalam (dihentakkan), (11)Maneuver dilakukan sebanyak tiga kali, dan diambil nilai terbaik, (12)Hasil dapat terlihat dari print out, dan dicocokkan sesua kategorik.

Hasil penelitian didapat dari perhitungan data yang diperoleh denga uji $\mathrm{t}$ berpasangan menggunakan SPSS versi 20.

yaitu 46,77 $\pm 3,16 \mathrm{~kg}$ dan rerata tinggi badan yaitu $150,6 \pm 3,37 \mathrm{~cm}$, yang menunjukkan bahwa subyek memiliki karakteristik fisik yang baik. Subyek berada dalam kategori status gizi yang baik hal ini ditunjukkan oleh rerata 
Tabel 1. Karakteristik Responden

\begin{tabular}{llllll}
\hline & N & MEAN & SD & MINIMUNM & MAXIMUM \\
\hline UMUR & 20 & 17.90 & 0.968 & 16 & 21 \\
BB & 20 & 46.7700 & 3.16512 & 40.20 & 52.60 \\
TB & 20 & 150.6150 & 3.37425 & 143.40 & 159.00 \\
IMT & 20 & 20.6240 & 1.34456 & 18.55 & 22.74 \\
\hline
\end{tabular}

Pada penelitian sebelumnya dikatakan bahwa kapasitas vital paru-paru seseorang dipengaruhi oleh indeks massa tubuhnya. Individu dengan IMT berlebih akan memiliki nilai kapasitas vital paru yang lebih kecil dibandingkan dengan yang memiliki IMT Normal. ${ }^{5}$ Peningkatan 1 unit IMT akan menyebabkan penurunan sebesar $0.5 \%$ pada kapasitas vital, kapasitas total paru dan volume residual. ${ }^{16}$

B. Heart Rate Monitoring

Monitoring heart rate menggunakan merek Omron, diakukan setiap kali latihan (6 kali dalam 2 minggu) dalam setiap latihan diambil 3 orang responden yang gerakannya dianggap paling baik, monitoring dilakukan pada orang yang berbeda setiap kali latihan sehingga hasil rata-rata monitoring heart rate dianggap mewakili semua responden. monitoring dilakukan setiap 5 menit selama 60 menit latihan zumba. Pada Gambar 1 dapat dilihat perbandingan rata-rata heart rate selama latihan Zumba di ambil dari menit ke-5 sampai menit ke 60 .

Tahap-tahap latihan dalam penelitian ini terdiri dari pemanasan atau warming up, latihan inti dan pendinginan atau cooling down. Warming up dalam penelitian ini dilakukan selama 15 menit dengan denyut jantung rata-rata 134 denyut per menit. Dilanjutkan dengan latihan inti selama 30 menit dengan denyut jantung rata-rata149 denyut per menit. Selanjutnya diakhiri dengan pendinginan selam 15 menit dengan denyut jantung rata-rata 138 denyut per menit. Intensitas latihan dalam penelitian ini termasuk dalam intensitas sedang tetapi pada subjek penelitian yang tidak rutin berolahraga (sedentary) dapat dianggap termasuk dalam intensitas tinggi.

\section{HR}

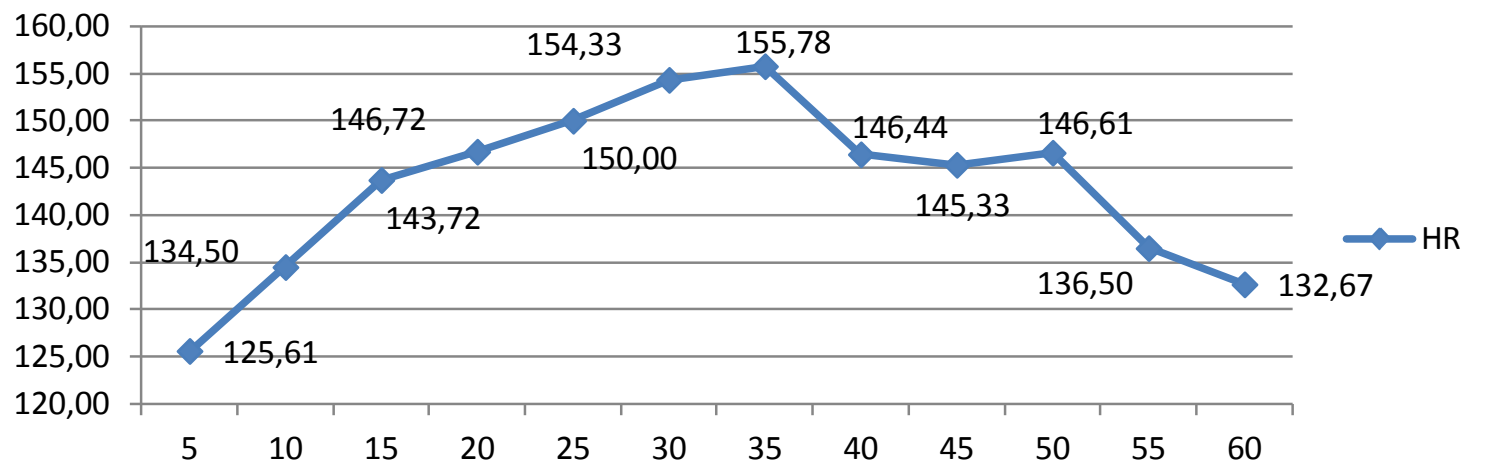

Gambar 1. Monitoring Heart Rate dari menit ke 5 hingga menit ke 60 
C. Analisis Data

1. Analisis Univariat

Rerata Kapasitas Ekspirasi

Paksa Satu Detik Pertama (FEV1)

sebelum dan sesudah latihan

Zumba dapat dilihat pada Tabel 3.

Nilai ekspirasi paksa dalam satu detik pertama diambil sebelum dan sesudah 2 minggu latihan Zumba. Berdasarkan hasil yang didapat, rerata nilai FEV1 sebelum latihan Zumba 2,4060 L dan sesudah latihan Zumba 2,4360 L, terlihat peningkatan rerata sebelum dan sesudah latihan Zumba.

Tabel 3 : perbandingan rerata nilai Kapasitas ekspirasi paksa satu detik

\begin{tabular}{lccc}
\hline FEV1 & N & Mean & $\begin{array}{l}\text { Standar } \\
\text { deviasi }\end{array}$ \\
\hline Sebelum & 20 & 2.4060 & 0.31098 \\
Sesudah & 20 & 2.4360 & 0.30516 \\
\hline
\end{tabular}

2. Analisis Bivariat

Nilai Kapasitas Ekspirasi Paksa dalam Satu Detik Pertama (FEV1) sebelum dan sesudah latihan Zumba selama 2 minggu menunjukkan hasil distribusi data normal . Karena didapatkan hasil distribusi data normal maka dilakukan uji beda dua rata-rata dua kelompok berpasangan (Paired $\mathrm{T}$ Test). Hasil yang diperoleh dari uji rata-rata dua kelompok berpasangan didapatkan $P=0,044$ $(P<0,05)$ hal ini menunjukkan bahwa terdapat perbedaan nilai Nilai Kapasitas Vital Paksa dalam satu detik pertama sebelum dan sesudah latihan Zumba selama 2 minggu.

3. Pengaruh Latihan Zumba terhadap fungsi paru
Berolahraga merupakan cara yang sangat baik untuk meningkatkan vitalitas fungsi paru. Pada keadaan istirahat, sebagian kapiler paru biasanya tertutup karena tekanan sirkulasi paru normalnya akan rendah dan tidak mampu membuka semua kapiler yang ada. Selama olahraga, tekana darah paru meningkat akibat peningkatan curah jantung sehingga banyak kapiler paru yang sebelumnya tertutup menjadi terbuka. Selama olahraga kurang lebih $15 \%$ dari 300 juta total alveolus teregang/terbuka dari pada normal karena peningkatan ventilasi. $^{11}$

Latihan fisik akan mempengaruhi fungsi pernapasan sehingga menjadi lebih efektif. Aktifitas fisik atau olahraga akan menyebabkan peningkatan daya tahan otot pernapasan sehingga fungsi pernapasan akan meningkat dan dengan demikian akan meningkatkan kebugaran jasmani yang akan berdampak dengan kualitas hidup yang lebih baik. $^{6}$

Dari hasil penelitian ini ditemukan perbedaan nilai FEV1 sebelum dan sesudah latihan dengan $P=0,044(P<0,05)$. Hal ini menunjukkan terdapat pengaruh latihan Zumba terhadap perubahan nilai fungsi paru dan dapat dikatakan kapasitas paru seseorang sudah mulai meningkat seteah 2 minggu latihan Zumba dan jika dilakukan latihan yang teratur dan kontinu akan lebih meningkatkan efisiensi otot pernapasan dan meningkatkan pemasukan oksigen ke dalam paru.

Hasil penelitian ini sesuai dengan penelitian sebelumnya yang dilakukan oleh Hidayati bahwa terdapat perbedaan nilai FEV1 yang bermakna pada sebelum dan sesudah latihan 
pembinaan jasmani militer berdasarkan uji statistic paired Ttest $P=0,00(P=0,05)$ dengan rata-rata nilai $\mathrm{FEV1}$ sebelum 0,05 liter dan sesudah 3,32 liter atau terdapat peningkatan sebesar $61 \%$ antara sebelum dan sesudah mengikuti latihan. ${ }^{14}$ MDS Hutapea dan Angeline Anglia dalam penelitiannya menemukan bahwa terdapat perbedaan yang signifikan antara nilai rata-rata FEV1 pada subjek yang aktif dan tidak aktif berolahraga $(P=0,00 ;<0,05)$ nilai FEV1 pada mahasiswa pria yang aktif berolahraga lebih tinggi dibandingkan yang tidak aktif berolahraga. $^{18}$ Penelitian yang dilakukan oleh Thompson $\mathrm{H}$ menemukan terdapat perbedaan peningkatan FEV1 pada pasien asma yang diberikan intervensi olahraga selama 2 bulan disbanding sebelum olahraga. $^{18,19}$ Dari beberapa penelitian di atas dapat disimpulkan bahwa terdapat pengaruh yang sangat besar antara latihan fisik dengan peningkatan volume dan fungsi paru.

\section{SIMPULAN}

Pada penelitian ini didapatkan bahwa latihan Zumba dapat mempengaruhi nilai FEV1. Berdasarkan hasil penelitian yang dilakukan terdapat perubahan rerata Nilai Kapasitas Ekspirasi Paksa Satu Detik Pertama (FEV1) sebelum dan sesudah latihan Zumba. Terjadi peningkatan nilai FEV1 setelah melakukan latihan Zumba selama 2 minggu dengan $P=0,044$.

\section{SARAN}

1. Untuk meningkatkan kapasitas fungsi paru diperlukan latihan yang rutin dan teratur.

2. Responden sebaiknya dikarantina beberapa hari sebelum dan selama penelitian agar dapat dikontrol dengan baik.
3. Pada penelitian selanjutnya dianjurkan untuk melakukan penelitian ini lebih dari 2 minggu agar didapatkan peningkatan fungsi paru yang lebih baik.

\section{UCAPAN TERIMA KASIH}

Ucapan terima kasih disampaikan kepada dr. Maya Moningka M.Sc (Dosen penguji I), Drs. Bahrun, MKs, (Dosen penguji II) dan kepada semua pihak yang baik secara langsung maupun tidak langsung telah menumbuhkan ide atau gagasan dalam pemikiran penulis sehingga dapat menyelesaikan artikel ini.

\section{DAFTAR PUSTAKA}

1. Muchtar. A F.2010.Be healthy be happy.Jakarta.PT Bhuana Ilmu Populer. p 207

2. Pusat Data dan Informasi Kementrian Kesehatan RI. Buletin jendela data dan informasi kesehatan,volume 2, semester 2 , 2012. Penyakit tidak menular.p 1.

3. World Health Organization (2011). Global Status report on noncommunicable disease 2010. World Health Organization.

4. World Health Organization (2011). Noncommunicable disease country profiles 2011 WHO global report, Geneva. World Health Organization.

5. Purwanto. Dampak senam aerobic terhadap daya tahan tubuh dan penyakit. Jurnal media ilmu keolahragaan Indonesia. 2011; volume 1, edisi 1.

6. Chaitra B, Narhare P, Puranik N,Maitri V. Moderate intensity aerobics training improves pulmonary functionin young Indian men. Biomedical Research 2012; 23 (2): 231-233

7. Thompson WR. World Wide Survey of Fitness Trends for 2013. ACSM Health Fitness J. 2012;16:14 
8. Luettgen M, Foster C, Doberstein S, Mikat R, and Porcari J. Zumba: is the "fitness-party" a good workout?. Journal of Sport Science and Medicine. 2012;11:357-58.

9. Luettgen M, Porcari JP, Foster C, Mikat R, Rodriguez-Morroyo J. Zumba : Sure It's Fun But Is It Effective? 2012

10. Warta Kesra. Tubuh Bugar, Otak Sehat Dengan Zumba. Edisi 158. 2012:26

11. Polii H. Pengaruh Senam Aerobik Intensitas Sedang dan Tinggi Terhadap Volume dan Kapasitas Paru Wanita [tesis].Manado : Universitas Sam Ratulangi; 2009.

12. Guyton A C, and Hall J E. Buku ajar fisiologi kedokteran. Edisi 11, EGC. Jakarta. 2007

13. Madina,DS. Nilai Kapasitas vital paru dan hubungannya dengan karakteristik fisik pada atlet berbagai cabang olahraga. Fakultas kedokteran Universitas Padjadjaran. 2007 [19 Mei 2012]: Available from: http://blog.uad.ac.id/novihardiniput ri/files/2011/12/NILAIKAPASITAS-VITAL-PARU.pdf

14. Hidayati I. Pengaruh latihan pembinaan jasmani militer terhadap nilai kapasitas vital paru dan volume ekspirasi paksa satu detik pertama siswa secaba di resimen induk daerah militer jaya (RINDAM JAYA) periode November 2011- Februari 2011 [skripsi]. [Jakarta]: Universitas Pembangunan Nasional "Veteran" 2012

15. Sugiyono. Metode Penelitian Kuantitatif Kualitatif dan r\&d. Bandung, Alfabeta; 2011. h. 91

16. Ristianingrum I, Rahmawati I, Rujito L. Hubungan antara indeks massa tubuh (IMT) dengan tes fungsi paru. Mandala of Health. 2010 Mei; volume 4: nomor 2. P 105

17. Mengkidi, D. Gangguan fungsi paru dan faktor-fakor yang mempengaruhinya pada karyawan PT. Semen Tonasa Pangkep Sulawesi Selatan[tesis]. Semarang;Universitas Diponegoro Semarang. 2006.

18. Hutapea M, Angladi E.

Perbandingan FEV1 (Forced Expiratori Volume in one second) Pada Mahasiswa yang Aktif dan yang Tidak Aktif Berolahraga. Ejournal.2013; volume 1.nomor 1. Available from:

http://ejournal.unsrat.ac.id/index.ph p/eclinic/article/view/3299/2842

19. Thompson H. Forced expiration exercices in asthma and their effect on FEV1. New Zealand Journal of Physiotherapy.2012.p48-50. 